\title{
Avaliação sensorial, físico-química e microbiológica do pirarucu (Arapaima gigas, Schinz 1822) durante estocagem em gelo
}

\author{
Sensorial, physicochemical and microbiological assessment of pirarucu \\ (Arapaima gigas, Schinz 1822) during ice storage
}

\section{Autores | Authors}

$\triangle$ Pedro Roberto de OLIVEIRA

Universidade Federal do Amazonas (UFAM)

Departamento de Ciências Pesqueiras Av. Gal Rodrigo Otávio Jordão Ramos,

3000

Campus Universitário CEP: 69077-000

Manaus/AM - Brasil e-mail:poliveira@ufam.edu.br

Rogério Souza de JESUS

Instituto Nacional de Pesquisas da Amazônia (INPA)

Coordenação de Tecnologia e Inovação (COTI)

Manaus/AM - Brasil e-mail:djesus@inpa.gov.br

Gilvan Machado BATISTA

Universidade Nitton Lins (UNINILTONLINS) Laboratório Central Manaus/AM - Brasil E-mail:gbatista@niltonlins.br

Edson LESSI

Instituto Nacional de Pesquisas da Amazônia (INPA)

Coordenação de Tecnologia e Inovação (COTI)

Manaus/AM - Brasil E-mail: elessi@inpa.gov.br

$\square$ Autor Correspondente / Corresponding Author

Recebido / Received: 11/09/2013 Aprovado / Approved: 24/02/2014 Publicado / Published: mar./2014

\section{Resumo}

O pirarucu é a espécie de peixe de maior valor econômico na Amazônia brasileira, e esse fato tem motivado crescente interesse dos piscicultores na sua exploração comercial. A finalidade do presente estudo foi medir as alterações sensoriais, físico-químicas e microbiológicas que ocorreram em exemplares de pirarucu estocados em gelo $\left(2 \pm 1^{\circ} \mathrm{C}\right)$. Amostras foram analisadas semanalmente, durante 36 dias, por meio de determinações do pH, Nitrogênio das bases voláteis totais (N-BVT), avaliação sensorial pelo Método de Índice de Qualidade (MIQ), textura instrumental e contagens microbiológicas. Foram também determinados a composição centesimal, o índice de rigor mortis e o rendimento da espécie. Os resultados mostraram que o tempo de vida útil para consumo, de acordo com a avaliação sensorial, foi de $27 \pm 0,5$ dias em gelo. As contagens de bactérias mesófilas e psicrófilas apresentaram valores máximos entre $10^{6}$ a $10^{7}(\mathrm{UFC} / \mathrm{g})$ e os índices de pH e N-BVT não apresentaram valores elevados durante todo o período de estocagem em gelo.

Palavras-chave: Conservação em gelo; N-BVT; Contagens bacterianas; Sistema MIQ.

\section{Summary}

Pirarucu is economically the most important fish species of the Brasilian Amazonia, and this fact has coming strong interest of the fishfarmers on this trading explotation. Thus the purpose of this study was to evaluate sensorial, physico-chemical and microbiological changes those occur in the pirarucu whole stored on ice $\left(2 \pm 1^{\circ} \mathrm{C}\right)$. Samples were analyzed every week, for 36 days, by determination of $\mathrm{pH}$, total volatile bases of nitrogen (N-TVB), sensory evaluation by the Quality Index Method (QIM), instrumental texture and bacterial counts. Additionally was determined the chemical composition, the rigor index and fish yield. The results showed the shelf life for consumption, according the sensorial evaluation was $27 \pm 0,5$ days on ice. The psychrophilic and mesophilic counts was between $10^{6}-10^{7}$ at 36 days of experiment and the $\mathrm{pH}$ and N-TVB values showed no significant elevated during ice storage.

Key words: Ice storage; N-TVB; Bacterial counts; QIM system. 


\section{Introdução}

O pirarucu é uma espécie nativa da região amazônica, que, na natureza, alcança até $200 \mathrm{~kg}$ de peso total, e sua elevada importância econômica tem motivado o interesse crescente na sua exploração comercial por criadores de peixes (PEREIRA-FILHO e ROUBACH, 2005). $O$ valor nutritivo do pescado está associado às condições da qualidade de seu frescor e a determinados fatores extrínsecos ou intrínsecos, especialmente a temperatura, que são relevantes para o processo de deterioração (HUSS, 1998; MEDINA et al., 2009).

O pescado é um alimento muito perecível, que passa por mudanças logo após a sua morte. A perda do frescor ocorre devido à degradação do músculo do pescado, que se inicia pela complexa combinação de processos bioquímicos, químicos e físicos. Durante os primeiros dias de estocagem em gelo, as enzimas endógenas, principalmente das vísceras e superfície do peixe, promovem a perda gradual de frescor, resultando na produção de substâncias com odor desagradável, e criam um meio favorável ao metabolismo bacteriano. A partir daí, as bactérias proliferam no músculo do peixe, acelerando o processo de deterioração (PACHECOAGUILAR et al., 2000; JESUS et al., 2001).

O rigor mortis é um fator que interfere diretamente na qualidade do pescado, porém o tempo em que o animal vai permanecer em rigor é variável, sendo que sua duração é dependente da quantidade de ATP e de glicogênio que o peixe possui antes de sua morte. A quantidade dessas reservas está diretamente relacionada com a forma de manejo recebida pelo animal, como manuseio, transporte e método de abate utilizados (ROBB e KESTIN, 2002; VIEGAS et al., 2012).

Adicionalmente, as características sensoriais envolvem uma série de atributos com base em critérios de aparência, textura, odor, cor e sabor, que, juntamente com a composição centesimal, especialmente a concentração de proteína e lipídios, influenciam a velocidade da deterioração e podem ser utilizados para medir a intensidade do processo de putrefação. Alguns parâmetros físico-químicos, como pH e N-BVT, o estabelecimento do rigor e a capacidade de retenção de água, ambos com reflexo na textura do pescado, também medem a intensidade da deterioração. $\mathrm{O}$ pH da carne de peixes frescos é um parâmetro que fornece informações sobre o estado de conservação do pescado, uma vez que o processo de deterioração altera os níveis de $\mathrm{pH}$ devido à decomposição de aminoácidos, porém o uso desta análise deve ser feito em conjunto com outros parâmetros (CHYTIRI et al., 2004; AKSE et al., 2008; ANDRÉS-BELLO et al., 2013).

A determinação de bases nitrogenadas voláteis (N-BVT) é um dos testes mais utilizados para determinar o grau de frescor dos peixes. As bases voláteis são produzidas pelas enzimas endógenas e de origem bacteriana, sendo responsável pela perda do frescor e aparecimento dos primeiros sinais de putrefação do pescado. Segundo Ogawa e Ogawa (1999), num peixe em excelente estado de frescor, o teor de N-BVT deve ser de 5 a $10 \mathrm{mg} \mathrm{N} / 100 \mathrm{~g}$ de amostra. O limite máximo de aceitação no Brasil é de $30 \mathrm{mg} / 100 \mathrm{~g}$ para pescado fresco, porém esse valor ainda é muito discutido pelos pesquisadores, por isso a necessidade de estudos em diferentes espécies (TEODORO et al., 2007).

O Método do Índice de Qualidade (MIQ) é um dos sistemas de avaliação sensorial atualmente mais empregados para avaliar a qualidade do pescado, criado na Europa como alternativa para o esquema tradicionalmente usado na Comunidade Europeia, e deve ser desenvolvido para cada espécie de peixe. Vários estudos têm mostrado que, para peixes estocados em gelo, existe relação linear entre os escores do MIQ e o tempo de estocagem, o que possibilita a estimativa do tempo restante de vida útil do pescado (BAIXASNOGUERAS et al., 2003; GUILLERM-REGOST et al., 2006; CARDENAS-BONILA et al., 2007; NIELSEN e GREEN, 2007).

Assim, tendo em vista o potencial de crescimento na exploração comercial do pirarucu, é necessária a realização de estudos concernentes à qualidade sensorial, físico-química e microbiológica após sua despesca e abate. O presente estudo foi proposto para avaliar a qualidade do pirarucu procedente de piscicultura, estocado em gelo por 36 dias, utilizando-se de determinações físico-químicas, contagens bacterianas e da avaliação sensorial, com o propósito de contribuir para a elaboração, a longo prazo, de uma tabela de avaliação de MIQ para a determinação da vida útil do pirarucu fresco.

\section{Material e métodos}

\subsection{Material}

Dezessete exemplares de pirarucu foram utilizados neste experimento, sendo todos da mesma origem genética. O manejo de cultivo foi idêntico para todos os peixes, que pertenciam a um mesmo lote, mantidos no mesmo local desde a desova até o abate, sendo alimentados com ração artificial seca, específica para peixes carnívoros.

Os pirarucus foram cultivados durante 12 meses em tanques de alvenaria de $200 \mathrm{~m}^{2}$, com densidade de 1 peixe/10m², na Coordenação de Pesquisas em Aquicultura (CPAQ) do Instituto Nacional de Pesquisas da Amazônia - INPA, na cidade de Manaus (AM). O comprimento total médio dos exemplares analisados foi $97,55 \mathrm{~cm}$ e o peso total médio de $7,85 \mathrm{~kg}$. 
Antes de serem abatidos por hipotermia, ficaram em jejum durante 24 horas. $O$ abate constou da imersão dos peixes em água gelada $\left(2 \pm 1^{\circ} \mathrm{C}\right)$ em caixa de isopor com capacidade para 170 litros, e o tempo para serem considerados mortos foi de 15 minutos. Os peixes foram transferidos para a Planta Piloto de Pescado do INPA, onde foram estocados em gelo, inteiros com vísceras, em caixas de isopor de 170 litros na proporção de 1:1 de gelo / peixe, sendo diariamente mantida essa proporção.

\subsection{Metodologia}

\subsubsection{Determinação do rendimento}

Para cada exemplar do pirarucu, foram medidos o comprimento total, o comprimento padrão e o peso total, sendo, em seguida, separadas as porções corporais (cabeça, vísceras, coluna, filé, escamas e pele), que foram pesadas em balança digital, marca Filizola, de fabricação nacional. Essas informações foram tabuladas em planilhas e foi calculada a porcentagem de cada parte, usando a seguinte fórmula:

Rendimento $(\%)=($ peso da porção corporal $/$ peso total $) \times 100$.

\subsubsection{Composição química}

Foram determinadas, sobre amostras das regiões dorsal e ventral dos exemplares de pirarucu, as concentrações de Umidade, Proteína Total (método de Kjehdahl) e Cinza, segundo AOAC (HORWITZ, 1990) e Lipídios Totais, pelo método de Soxhlet com extração por hexano (IAL, 2008). O teor de carboidratos foi calculado por diferença da soma das concentrações anteriormente determinadas em relação a 100\%.

\subsubsection{Análises físico-químicas}

$\mathrm{O} \mathrm{pH}$ e N-BVT foram determinados de acordo com as Normas Analíticas do Instituto Adolfo Lutz (IAL, 2008).

\subsubsection{Textura instrumental}

As medidas foram realizadas em analisador de textura TA.XT2 (Stable Micro System, Surrey, UK) sobre amostras de filés cortados nas seguintes dimensões: $2,0 \mathrm{~cm}$ de espessura $\times 3,0 \mathrm{~cm}$ de largura $\times 3,0 \mathrm{~cm}$ de comprimento, e também sobre o peixe inteiro durante a fase de rigor mortis. Os ensaios foram realizados com amostras à temperatura de $10{ }^{\circ} \mathrm{C}$, velocidade pré-teste e teste de $2,0 \mathrm{~mm} / \mathrm{s}$, com a sonda de referência P/05S, conforme Sigurgisladottir et al. (1999).

\subsection{5 Índice de rigor mortis}

O Índice de Rigor (IR) foi determinado conforme metodologia de Bito et al. (1983), com medidas em intervalos de 30 minutos, de maneira a identificar quatro fases: início do rigor, em rigor, rigor total e resolução do rigor, sendo calculado pela seguinte equação: $\operatorname{IR}(\%)=($ Lo - L) / Lo $\times 100$, onde Lo é a distância imediatamente após a morte e $\mathrm{L}$ é a distância medida ao longo do tempo.

\subsubsection{Contagens microbiológicas}

Foram realizadas semanalmente sobre amostras de $50 \mathrm{~g}$ do peixe estocado em gelo, retiradas a $5,0 \mathrm{~cm}$ abaixo da nadadeira dorsal, constando de: contagem de mesófilos a $35^{\circ} \mathrm{C}$, contagem de psicrófilos a $20^{\circ} \mathrm{C}$, contagem de psicrotróficos a $7{ }^{\circ} \mathrm{C}$, bolores e leveduras e do número de coliformes totais, fecais e E. coli (NMP), seguindo Lanara (1981) e ICMSF (1983).

\subsubsection{Análises sensoriais}

Foram realizadas semanalmente por painel treinado de seis julgadores constituído de pesquisadores e técnicos com experiência nesse tipo de avaliação, pertencentes à área de Tecnologia de Alimentos do INPA e da UFAM, constando de avaliações físicas sobre o peixe inteiro e de provas de degustação sobre os filés cozidos. A análise sensorial física foi realizada com uso de esquema do Método do Índice de Qualidade (MIQ), desenvolvido especificamente para o pirarucu a partir do método de Larsen et al. (1992), conforme Tabela 1. Para as análises do peixe cozido, as amostras foram colocadas em cápsulas de alumínio e cozidas a $95^{\circ} \mathrm{C}$ por 3 minutos em estufa com circulação de ar ou cozidas em vapor durante 7 minutos, sendo preparadas 12 amostras por sessão, as quais foram codificadas e servidas em duplicatas, para verificação se havia diferença quanto ao tipo de cocção utilizado.

\subsubsection{Análise estatística}

A análise estatística constou da aplicação de teste-t de Student para dados pareados e cálculos de parâmetros de tendência central: média aritmética e desvio padrão. Nas determinações físico-químicas e sensoriais, foi empregado modelo de análise de regressão com o tempo de estocagem, sendo usado para análise dos dados o software Minitab 14.

\section{Resultados e discussão}

O rendimento médio obtido para o filé de pirarucu, sem pele e sem escamas, foi de $41,41 \%$, que pode ser considerado adequado tecnologicamente. Esse rendimento está de acordo com dados relatados para filés de pirarucu analisados por Dias (1983) e Imbiriba (2001). Quanto à homogeneidade das amostras, observou-se que o coeficiente de variação, tanto do comprimento total médio como do peso total médio, foi inferior a 10\%, mostrando baixa dispersão dos dados. 
Avaliação sensorial, físico-química e microbiológica do pirarucu (Arapaima gigas, Schinz 1822) durante estocagem em gelo OLIVEIRA, P. R. et al.

A Tabela 2 apresenta o Índice de Rigor (IR), o pH e a textura em relação ao período de tempo. O rigor mortis a $100 \%$ provavelmente ocorreu entre 60 e 90 minutos após a morte. O menor valor medido do $\mathrm{pH}$ foi 6,48 aos 60 minutos, certamente pela alta formação de ácido láctico, enquanto o valor de dureza (textura instrumental) foi de $1474 \mathrm{~g}$, refletindo o elevado grau de rigor. Dados da literatura indicam que, nessa fase, os peixes apresentam diferenças quanto ao tempo de rigor mortis e valor de $\mathrm{pH}$, enfatizando a influência do abate, da alimentação e da condição bioquímica das espécies como fatores que remetem a valores diferenciados nos parâmetros medidos entre as espécies (SCHERER et al., 2005; ROTH et al., 2006; KRISTOFFERSEN et al., 2006).

O curto tempo para a entrada em rigor do pirarucu pode ser devido ao seu tamanho reduzido e idade de

Tabela 1. Esquema do Método do Índice de Qualidade (MIQ) para o pirarucu.

\section{Parâmetro Características Pontos}

\begin{tabular}{|c|c|c|c|}
\hline & & & \\
\hline & & 0 & Brilhante, resplandecente \\
\hline & Pele/Escamas & 1 & Brilhante \\
\hline & & 2 & Opaca \\
\hline & & 0 & Mole, em pré-rigor \\
\hline & & 1 & Duro, em rigor mortis \\
\hline & Textura/Dureza & 2 & Elástico \\
\hline Aparência geral & & 3 & Firme \\
\hline & & 4 & Suave \\
\hline & Flacticidado & 0 & Não marcado pela pressão \\
\hline & clasticiuade & 1 & Marcado pela pressão \\
\hline & & 0 & Ausência total de "off-flavour" \\
\hline & Odor & 1 & Leve presença de "off-flavour" \\
\hline & & 2 & Presença de "off-flavour" \\
\hline & Trancnarôncia & 0 & Claros \\
\hline & 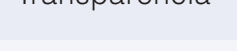 & 1 & Opacos \\
\hline Olhos & & 0 & Normal \\
\hline & Forma & 1 & Planos \\
\hline & & 2 & Fundos \\
\hline & Cor & 0 & Vermelho característico \\
\hline & ( & 1 & Pálida, descolorida, marrom \\
\hline Guelras & & 0 & Frescas, algas \\
\hline Nictilas & Odor & 1 & Neutro \\
\hline & not & 2 & Doce/ligeiramente azedo \\
\hline & & 3 & Ágrio/Azedo \\
\hline & Total & 16 & \\
\hline
\end{tabular}

Tabela 2. Índice de Rigor, pH e textura em relação ao tempo de estocagem.

\begin{tabular}{|c|c|c|c|c|}
\hline \multirow{2}{*}{ Tempo (min) } & \multicolumn{2}{|c|}{ Índice de Rigor } & \multirow{2}{*}{$\mathrm{pH}^{(2)}$} & \multirow{2}{*}{$\begin{array}{c}\text { Textura }^{(2)} \\
\text { Dureza (g) }\end{array}$} \\
\hline & Manhã (1) & Tarde ${ }^{(1)}$ & & \\
\hline 0 & - & - & $6,58 \pm 0,03$ & $1006,33 \pm 24,51$ \\
\hline 30 & $74,44 \pm 6,66^{a}$ & $58,54 \pm 1,72^{a}$ & $6,52 \pm 0,01$ & $1009,57 \pm 14,45$ \\
\hline 60 & $82,70 \pm 7,06^{a}$ & $76,68 \pm 5,41$ a & $6,48 \pm 0,01$ & $1474,00 \pm 14,18$ \\
\hline 90 & $72,89 \pm 5,85^{a}$ & $47,43 \pm 7,23^{a}$ & $6,52 \pm 0,03$ & $1072,33 \pm 28,73$ \\
\hline 120 & $56,04 \pm 12,05^{a}$ & $29,52 \pm 1,05^{b}$ & $6,57 \pm 0,01$ & $1012,87 \pm 12,68$ \\
\hline 150 & $45,98 \pm 6,344^{a}$ & $6,36 \pm 0,37 \mathrm{~b}$ & $6,67 \pm 0,02$ & $1031,94 \pm 21,44$ \\
\hline 180 & $36,74 \pm 6,15^{a}$ & $5,23 \pm 0,22^{b}$ & $6,68 \pm 0,02$ & $1028,41 \pm 34,54$ \\
\hline
\end{tabular}

(1) Mesma letra na linha para o Índice de Rigor indica que não há diferença estatística ( $p<0,05), n=3$. (2) Medido em 3 exemplares no período da manhã, $n=3$. 
12 meses, pois a duração e a intensidade do rigor mortis é mais breve em peixes jovens, além de depender do método de abate. A curva ajustada do Índice de Rigor apresentou melhor correlação com o modelo polinomial. Assim, tanto para os peixes abatidos no período da tarde (IRT $\left.=-0,0069 x^{2}+1,2714 x+18,5 ; R^{2}=0,6788\right)$ como para aqueles abatidos no período da manhã (IRM $=-0,0063 x^{2}+0,9762 x+17,69 ; R^{2}=0,641$ ), confirma-se o fato de que peixes jovens abatidos por hipotermia apresentam o início do rigor mortis em poucos minutos (HUSS, 1998).

A Tabela 3 apresenta valores da composição centesimal de duas regiões corpóreas: a ventral e a dorsal. Pode-se observar que somente os valores da concentração de lipídios apresentam diferença significante estatisticamente a $p<0,05$ entre as regiões dorsal e ventral, sendo superior nesta última. Do ponto de vista tecnológico, esta característica é importante para o tempo de vida do produto, pois a oxidação dos lipídios acarreta a produção de compostos orgânicos indesejáveis nas regiões gordas do pescado.

Conforme a Tabela 4, durante o período de estocagem em gelo de 36 dias, o valor de $\mathrm{pH}$ muscular variou entre 6,67 $\pm 0,01$ e 7,09 $\pm 0,02$, enquanto que 0 valor do N-BVT variou entre 6,65 $\pm 1,35$ e 18,85 $\pm 0,16$ $\mathrm{mgN} / 100 \mathrm{~g}$, não chegando a alcançar o limite máximo de $30 \mathrm{mgN} / 100 \mathrm{~g}$ da legislação vigente. Esses dados confirmam os valores de N-BVT encontrados para espécies de peixes de água doce nativos da Amazônia,

Tabela 3. Composição centesimal do músculo do pirarucu em duas regiões do corpo.

\begin{tabular}{ccc}
$\begin{array}{c}\text { Determinações } \\
(\%)\end{array}$ & Dorso $^{(1)}$ & Ventre $^{(1)}$ \\
\hline Umidade & $79,51 \pm 0,52^{a}$ & $77,88 \pm 0,53^{a}$ \\
Proteína & $17,56 \pm 0,12^{a}$ & $16,10 \pm 0,37^{a}$ \\
Lipídios & $0,62 \pm 0,02^{a}$ & $2,49 \pm 0,03^{\text {b }}$ \\
Cinza & $0,87 \pm 0,06^{a}$ & $0,84 \pm 0,05^{a}$ \\
Carboidratos $^{(2)}$ & 1,44 & 2,69 \\
\hline
\end{tabular}

${ }^{(1)}$ Média \pm desvio padrão $(n=3)$, mesma letra na linha indica que

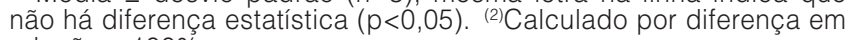
relação a 100\%. obtidos em trabalhos anteriores (JESUS et al., 2001; ANDRADE et al., 2010; CARTONILHO e JESUS, 2011).

Fazendo a correlação entre o tempo de estocagem em gelo com $\mathrm{pH}$ e com N-BVT, calculada a $\mathrm{p}<0,05$, foram obtidas as seguintes equações: $\mathrm{pH}=6,7189+0,0115 \mathrm{x}$ Tempo $\left(R^{2}=0,58\right)$ e N-BVT $=9,0111+0,3152 \times$ Tempo $\left(R^{2}=0,57\right)$, sendo observada uma tendência ascendente da curva. Assim, as correlações mostradas entre o pH com o tempo e N-BVT com o tempo foram de $58 \%$ e $57 \%$, respectivamente, que podem ser consideradas positivas.

A qualidade sensorial do peixe inteiro no sistema $\mathrm{MIQ}$ mostrou que o tempo limite para o consumo humano ficou entre 26 e 28 dias, quando foi atingido o nível de aceitabilidade máximo de 14 pontos, que havia sido determinado anteriormente durante o período de pré-observações, sendo que também foram realizadas análises do sabor e odor do peixe cozido, com limite de rejeição estabelecido em 5,5 pontos (Tabela 4). As características mais afetadas nos primeiros dias foram: a descoloração das guelras e a perda da concavidade dos olhos, que aos 6 dias de gelo já estavam opacos, com 12 dias de estocagem apresentavam-se côncavos e, aos 24 dias de gelo, a região ocular apresentava-se inteiramente enegrecida. Desse modo, foi estabelecida a curva de regressão entre os pontos atribuídos, tendo como resultado a relação linear entre os escores e 0 tempo de estocagem: $\mathrm{MIQ}=1,4286+0,4571 \times$ Tempo, $R^{2}=0,92, p<0,05$, com intervalo de 0,5 dia para mais ou para menos. Essa tendência de relação linear está em concordância com Nielsen e Green (2007) e CardenasBonilla et al. (2007).

A análise microbiológica dos filés de pirarucu, durante o período de estocagem em gelo por 36 dias, mostrou que na contagem das bactérias psicrotróficas e psicrófilas houve maior intensidade de crescimento a partir do $21^{\circ}$ dia, alcançando contagem próxima de 6 $\log$ UFC/g. As bactérias mesófilas apresentaram menor crescimento provavelmente em função da estocagem em gelo. Não houve crescimento de bactérias coliformes termotolerantes, nem de bolores e leveduras. Essas

Tabela 4. Valores de N-BVT, pH e escores sensoriais do pirarucu estocado em gelo.

\begin{tabular}{|c|c|c|c|c|c|}
\hline $\begin{array}{l}\text { Tempo } \\
\text { (dias) }\end{array}$ & $\begin{array}{c}\mathrm{N}-\mathrm{BVT} \\
(\mathrm{mgN} / 100 \mathrm{~g})^{(1)}\end{array}$ & pH ${ }^{(1)}$ & $\begin{array}{l}\text { Escores } \\
\mathrm{MIQ}^{(1,2)}\end{array}$ & $\begin{array}{c}\text { Sabor do peixe } \\
\text { cozido(1) }^{(1)}\end{array}$ & $\begin{array}{l}\text { Odor do peixe } \\
\text { cozido }^{(1)}\end{array}$ \\
\hline 0 & $6,65 \pm 1,35$ & $6,79 \pm 0,01$ & $0 \pm 0,00$ & $10 \pm 0,00$ & $10 \pm 0,00$ \\
\hline 6 & $15,64 \pm 1,72$ & $6,67 \pm 0,01$ & $2,4 \pm 2,61$ & $9,8 \pm 0,45$ & $10 \pm 0,00$ \\
\hline 12 & $7,44 \pm 0,06$ & $6,81 \pm 0,01$ & $8,8 \pm 1,48$ & $8,6 \pm 0,55$ & $8,4 \pm 0,56$ \\
\hline 18 & $17,81 \pm 0,94$ & $7,02 \pm 0,01$ & $12,2 \pm 1,30$ & $7,0 \pm 0,10$ & $7,0 \pm 0,45$ \\
\hline 24 & $17,64 \pm 2,28$ & $7,02 \pm 0,03$ & $13,8 \pm 0,84$ & $6,8 \pm 0,84$ & $6,6 \pm 1,14$ \\
\hline 30 & $18,85 \pm 0,16$ & $7,08 \pm 0,03$ & $14,6 \pm 0,89$ & $5,6 \pm 0,56$ & $5,6 \pm 0,56$ \\
\hline 36 & $18,76 \pm 0,46$ & $7,09 \pm 0,02$ & $15,8 \pm 0,45$ & $4,4 \pm 0,55$ & $4,6 \pm 0,55$ \\
\hline
\end{tabular}

(1)Média \pm desvio padrão, n=3; (2)Método do Índice de Qualidade. 
contagens estiveram dentro dos limites recomendados por Huss (1998).

Na Figura 1, observa-se nas curvas a fase de adaptação dos microrganismos ao ambiente, a fase de estabilidade e, em seguida, a fase de crescimento exponencial. Em função da baixa quantidade inicial de microrganismos psicrófilos, a deterioração das espécies tropicais torna-se mais lenta do que em peixes de águas temperadas e frias, e, certamente, por isso, a espécie estudada ter apresentado extenso tempo de vida útil em gelo. Assim, provavelmente, o processo de degradação ocorreu mais pela ação das enzimas musculares do que pelas enzimas de origem bacteriana.

Os dados de textura instrumental exibiram tendência decrescente conforme mostrado na Figura 2. No entanto, não apresentou alterações significativas após 14 dias de estocagem, indicando que as alterações na textura da carne não foram perceptíveis a partir da

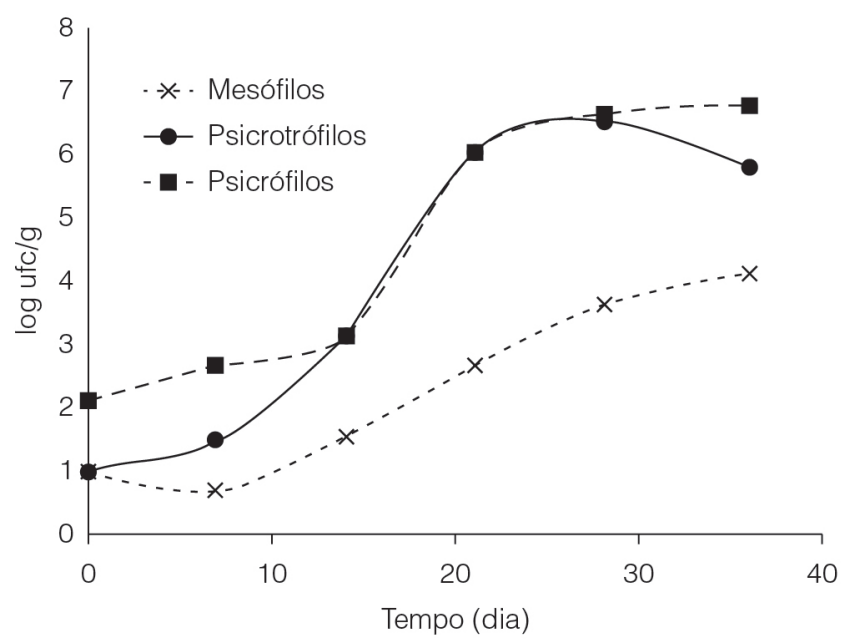

Figura 1. Contagem total de bactérias (log UFC/g) no pirarucu estocado em gelo.

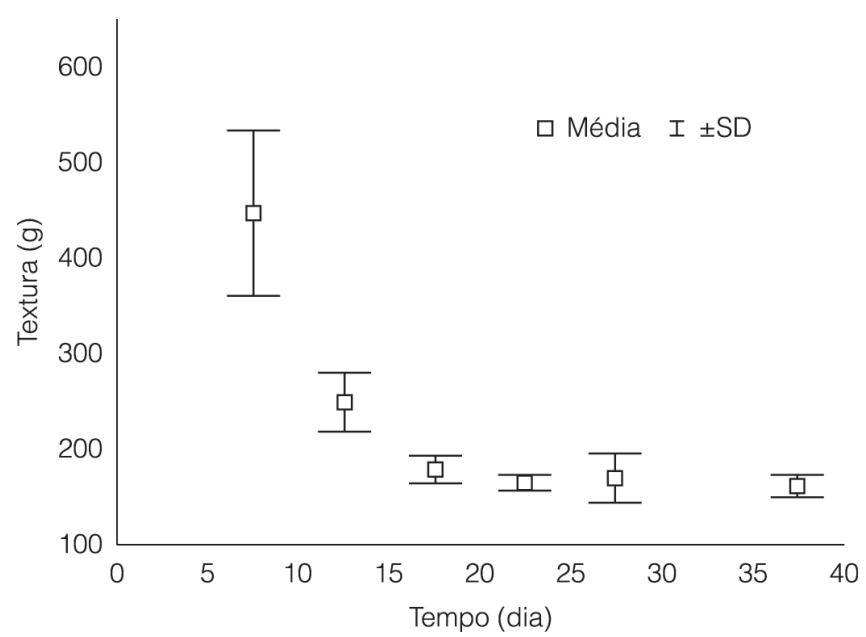

Figura 2. Textura (g) no pirarucu estocado em gelo. terceira semana de análises, provavelmente em função da perda de líquido na superfície do músculo ser mais acentuada entre o sétimo e o décimo quarto dias de estocagem em gelo. Tendência semelhante foi encontrada por Guillerm-Regost et al. (2006).

\section{Conclusões}

Com base nos resultados obtidos, pode ser concluído que o rigor mortis total do pirarucu ocorreu uma hora após o abate e a estocagem em gelo. Nessas condições experimentais, foi constatado que a concentração lipídica da região corpórea dorsal do pirarucu o classifica como pescado magro, porém seu teor de gordura na região ventral classifica-o como pescado semigordo. As determinações de $\mathrm{pH}$ e N-BVT não foram bons índices de avaliação da qualidade do pirarucu, porém a textura instrumental e as contagens bacteriológicas foram bons parâmetros indicadores da qualidade do pescado, principalmente nas primeiras semanas de avaliação. Tanto as análises sensoriais do pescado inteiro pelo sistema MIQ como a degustação dos filés de pescado cozidos apresentaram alta correlação com o tempo de estocagem, revelando-se excelente método para avaliar o frescor do pirarucu cultivado estocado em gelo, estabelecendo a sua vida útil para consumo em $27 \pm 0,5$ dias em gelo.

\section{Agradecimentos}

Ao Ministério da Pesca e Aquicultura (MPA) e ao CNPq pelo suporte financeiro (Edital CNPq N016/2006). Ao pesquisador Dr. Manoel Pereira Filho (in memoriam) pela cessão dos pirarucus cultivados na CPAQ/INPA.

\section{Referências}

ANDRADE, E. G.; JESUS, R. S.; FALCÃO, P. T.; LESSI, E. "Minced" de pescados de la acuicultura amazônica de calidad. Infopesca Internacional, Montevidéo, n. 44, p. 39-43, 2010.

ANDRÉS-BELLO, A.; BARRETO-PALACIOS, V.; GARCÍASEGOVIA, P.; MIR-BEL, J. E.; MARTíNEZ-MONZÓ, J. Effect of $\mathrm{pH}$ on color and texture of food products. Food Engineering Reviews, New York, v. 5, n. 3, p. 158-170, 2013. http://dx.doi. org/10.1007/s12393-013-9067-2

AKSE, L.; BIRKELAND, S.; TOBIASSEN, T.; JOENSEN, S.; LARSEN, R. injection-salting and cold-smoking of farmed atlantic cod (Gadus morhua L.) and atlantic salmon (Salmo salar L.) at different stages of rigor mortis: effect on physical properties. Journal of Food Science, Chicago, v. 73, n. 8, p. 378-382, 2008. http://dx.doi.org/10.1111/j.1750-3841.2008.00917.x

BAIXAS-NOGUERAS, S.; BOVER-CID, S.; VECIANA-NOGUES, T.; NUNES, M. L.; VIDAL-CAROU, M. C. Development of a quality index method to evaluate freshness in mediterranean 
Avaliação sensorial, físico-química e microbiológica do pirarucu (Arapaima gigas, Schinz 1822) durante estocagem em gelo OLIVEIRA, P. R. et al.

hake (Merluccius merluccius). Journal of Food Science Chicago, v. 68, n. 3, p. 1067-1071, 2003. http://dx.doi. org/10.1111/j.1365-2621.2003.tb08289.x

BITO, M.; YAMADA, K.; MIKUMO, Y.; AMANO, K. Difference in the mode of rigor mortis among some varieties of fish by modified cutting's method. Bulletin of Tokai Regional Fisheries Research Laboratory, Tokio, n. 109, p. 89-93, 1983.

CARDENAS-BONILLA, A.; SVEINSDOTTIR, K.; MARTINSDOTTIR, E. Development of quality index method (QIM) scheme for fresh cod (Gadus morhua) fillets and application in shelf life study. Food Control, Amsterdan, v. 18, n. 4, p. 352-358, 2007.

CARTONILHO, M. M.; JESUS, R. S. Qualidade de cortes de tambaqui cultivado. Pesquisa Agropecuária Brasileira, Brasília, v. 46, n. 4, p. 344-350, 2011. http://dx.doi.org/10.1590/ S0100-204X2011000400002

CHYTIRI, S.; CHOULIARA, I.; SAVVAIDIS, I. N.; KONTOMINAS, M. G. Microbiological, chemical and sensory assessment of iced whole and filleted aquacultured rainbow trout. Journal of Food Microbiology, New York, v. 21, n. 2, p. 157-165, 2004. http:// dx.doi.org/10.1016/S0740-0020(03)00059-5

DIAS, A. F. Salga e Secagem do Pirarucu, Arapaima gigas (CUVIER, 1929) Com a Aplicação de Coletores Solares. 1983. 133 f. Dissertação (Mestrado em Biologia de Água Doce e Pesca Interior)-Universidade Federal do Amazonas, Manaus.

GUILLERM-REGOST, C.; HAUGEN, T.; NORTVEDT, R.; CARLEHÖUG, M.; LUNESTAD, B. T.; KIESSLING, A.; RØRÁR, A. M. B. Quality characterization of farmed atlantic halibut during ice storage. Journal of Food Science, Chicago, v. 71, n. 2, p. 83-90, 2006. http://dx.doi.org/10.1111/j.1365-2621.2006. tb08926.x

HORWITZ, W. (Ed.). Official Methods of Analysis of the Association off Official Analytical Chemists. 15. ed. Washington: AOAC, 1990. $960 \mathrm{p}$

HUSS, H. H. (Ed.). El Pescado Fresco: su Calidad y Cambios de su Calidad. Roma: FAO, 1998. 202 p. (Documento Tecnico de Pesca, n. 348).

IMBIRIBA, E. P. Potencial da criação de pirarucu. Acta Amazônica, Manaus, v. 31, n. 2, p. 299-316, 2001.

INSTITUTO ADOLFO LUTZ - IAL. Métodos Fisico-químicos para Análise de Alimentos. 4. ed. São Paulo: IAL, 2008. 1020 p. Versão eletrônica.

INTERNATIONAL COMMISSION ON MICROBIOLOGICAL SPECIFICATION FOR FOODS - ICMSF. Microorganisms in Food Sampling for Microbiological Analysis: Principle and Scientific Application. 2. ed. Canadá: ICMSF, 1983. p. 181-196.

JESUS, R. S.; LESSI, E.; TENUTA FILHO, A. Estabilidade química e microbiológica de "minced fish" de peixes amazônicos durante o congelamento. Ciência e Tecnologia de Alimentos, Campinas, v. 21, n. 2, p. 144-148, 2001. http://dx.doi. org/10.1590/S0101-20612001000200004

KRISTOFFERSEN, S.; TOBIASSEN, T.; STEINSUND, V.; OLSEN, R. L. Slaughter stress, postmortem muscle ph and rigor development in farmed atlantic cod (Gadus morhua). International Journal of Food Science and Technology, Oxford, v. 41, n. 7, p. 861-864, 2006. http://dx.doi.org/10.1111/ j.1365-2621.2005.01149.x

LABORATÓRIO NACIONAL DE REFERÊNCIA ANIMAL - LANARA. Métodos Analíticos Oficiais Para Controle de Produtos de Origem Animal e seus Ingredientes. Brasília: Ministério da Agricultura, 1981. $112 \mathrm{p}$.

LARSEN, P.; HELDBO, J.; JESPERSEN, C. M.; NIELSEN, J. Development of a standard for quality assesment on fish consumption. In: HUSS, M.; LISTON, J. (Ed.). Quality assurance in the fish industry. Amsterdam: Elsevier, 1992. p. 351-358.

MEDINA, I.; GALLARDO, J. M.; AUBOURG, S. P. Quality preservation in chilled and frozen fish products by employment of slurry ice and natural antioxidants. International Journal of Food Science and Technology, Oxford, v. 44, n. 8, p. 14671479, 2009. http://dx.doi.org/10.1111/j.1365-2621.2009.02016.x

NIELSEN, D.; GREEN, D. Developing a quality index grading tool for hybrid striped bass (Morone saxatilis x Morone chrysops) based on the quality index method. International Journal Food Science and Technology, Oxford, v. 42, n. 1, p. 86-94, 2007. http://dx.doi.org/10.1111/j.1365-2621.2006.01216.x

OGAWA, M.; OGAWA, N. B. P. Alterações do pescado postmortem. In: OGAWA, M.; MAIA, E. L. (Ed.). Manual de Pesca. São Paulo: Livraria Varela, 1999. p. 113-137.

PACHECO-AGUILAR, R.; LUGO-SÁNCHEZ, M. E.; ROBLESBURGUEÑO, M. R. Postmortem biochemical and functional characteristic of monterey sardine muscle stored at $0^{\circ} \mathrm{C}$. Journal of Food Science, Chicago, v. 65, n. 1, p. 40-47, 2000. http:// dx.doi.org/10.1111/j.1365-2621.2000.tb15953.x

PEREIRA FILHO, M.; ROUBACH, R. Criação de Pirarucu. In: BALDISSEROTO, B.; GOMES, L. C. (Org.). Criação de Espécies Nativas de Peixes. Santa Maria: UFSM, 2005. p. 37-66. Volume único.

ROBB, D. H. F.; KESTIN, S. C. Methods used to kill fish: field observations and literature reviewed. Animal Welfare, Hertfordshire, v. 11, n. 3, p. 269-282, 2002.

ROTH, B.; SLINDE, E.; ARILDSEN, J. Pre or post mortem muscle activity in atlantic salmon (Salmo salar): the effect on rigor mortis and the physical properties of flesh. Aquaculture, Oxford, v. 257 , n. $1-4$, p. 504-510, 2006. http://dx.doi.org/10.1016/j. aquaculture.2005.10.021 
Avaliação sensorial, físico-química e microbiológica do pirarucu (Arapaima gigas, Schinz 1822) durante estocagem em gelo OLIVEIRA, P. R. et al.

SCHERER, R.; AUGUSTI, P. R.; STEFFENS, C.; BOCHI, V. C.; HECKTHEUER, L. H.; LAZZARI, R.; RADÜNZ NETO, J.; POMBLUM, S. C. G.; EMANUELLI, T. Effect of slaughter method on postmortem changes of grass carp (Ctenopharyngodon idella) stored in ice. Journal of Food Science, Chicago, v. 70, n. 5, p. 348-353, 2005. http://dx.doi.org/10.1111/j.1365-2621.2005. tb09965.x

SIGURGISLADOTTIR, S.; HAFSTEINSSON, H.; JONSSON, A.; LIE, O.; NORTVEDT, R.; THOMASSEN, M.; TORRISSEN, O. Textural properties of raw salmon fillets as related to sampling method. Journal of Food Science, Chicago, v. 64, n. 1, p. 99-104, 1999. http://dx.doi.org/10.1111/j.1365-2621.1999. tb09869.x

TEODORO, A. J.; ANDRADE, E. C. B.; MANO, S. B. Avaliação da utilização de embalagem em atmosfera modificada sobre a conservação de sardinhas (Sardinella brasiliensis). Ciência e Tecnologia de Alimentos, Campinas, v. 27, n. 1, p. 158-161, 2007. http://dx.doi.org/10.1590/S0101-20612007000100028

VIEGAS, E. M. M.; PIMENTA, F. A.; PREVIERO, T. C.; GONÇALVES, L. U.; DURÃES, J. P.; RIBEIRO, M. A. R.; OLIVEIRA FILHO, P. R. C. Métodos de abate e qualidade da carne de peixe. Archivos de Zootecnia, Córdoba, v. 61, n. 1, p. 41-50. 2012. 